\title{
A Novel Model of Adoption of M-Commerce in Saudi Arabia
}

\author{
Yahya AlQahtani \\ dept. of Computer science \\ King Khalid University \\ dept. of Informatics \\ University of Sussex \\ Brighton, United Kingdom \\ ya227@sussex.ac.uk
}

\author{
Natalia Beloff \\ dept. of Informatics \\ University of Sussex \\ Brighton, United Kingdom \\ N.Beloff@sussex.ac.uk
}

\author{
Martin White \\ dept. of Informatics \\ University of Sussex \\ Brighton, United Kingdom \\ martinwh@sussex.ac.uk
}

\begin{abstract}
The market of Saudi Arabia offers considerable potential for the success of mobile commerce (m-commerce) technology. In this context, this study aims to investigate the factors that influence the intentions of Saudi citizens and firms to use m-commerce technology. This study paper advances the literature by proposing a novel model to investigate the motivations behind adopting $\mathrm{m}$-commerce in Saudi Arabia. The model defines factors that influence both customer and provider intentions of adopting $\mathrm{m}$-commerce. The paper also outlines the methodology to be followed to evaluate the proposed model.

Index Terms-acceptance model, adoption of m-commerce,
\end{abstract} Saudi Arabia

\section{INTRODUCTION}

$\mathbf{M}$ OBILE commerce (m-commerce) is the use of mobile and Internet technologies to conduct transactions for the sake of accessing information, interacting with a service, or purchasing a product [1]. It is a considerable extension to electronic commerce, which appeared in the 1990s and reshaped the business models of many industries. M-commerce provides the benefits of ubiquitous trade anytime and anywhere, thanks to advancements in wireless technologies and the growth of the number of mobile devices.

M-commerce technology has been widely adopted by large-, medium-, and small-scale enterprises. This technology helps enterprises improve their performance and their customer experiences. It allows personalising services based on customer interactions with the Internet in general and m-commerce in particular. Once customers download a m-commerce application on their devices, they become easily reachable by enterprises to send adverts to motivate them to purchase their products and services. The results of this have been demonstrated in increased growth rates and higher profits [2].

Many scholars hold the view that the above advantages of m-commerce motivated the adoption of this technology in developing countries. Those countries provide considerable market for ICT-based services [3, 4]. One case is the country of Saudi Arabia, which is the focus of this paper, where mcommerce is increasingly gaining attention [5]. The country has significant potential for m-commerce providers. First, it has a considerable number of smartphone users. In 2019,
$80.7 \%$ of the population used a smartphone. This percent is expected to reach $97.1 \%$ in 2025 [6]. Second, there is clear governmental interest in advancing the adoption of novel technologies and services in the Saudi market as part of the government 2030 vision, which aims to significantly transform the Saudi economy [7]. This interest is expected to attribute to significant investments that aim to improve mobile technologies. The Saudi private sector is reacting with the government 2030 vision by increasingly investing in the IT sector. This includes utilising new technologies that is not yet popular in Saudi Arabia and promoting existing technologies [8].

On the question of accepting a new technology, several models have been proposed to understand the factors that motivate users to adopt new technology. These include TAM [9], UTAUT [10], and TRA [11], among others. Rondan-Cataluña et al. [12] compare the different versions of popular technology acceptance models. However, briefly we describe the most common models and justify our choice. UTAUT provides a unified framework for understanding both the users' intentions to adopt an innovation and the posterior behaviour. TRA asserts that a person's behaviour is greatly influenced not merely by bias itself but also by personal opinions and expectations. TAM is based on the belief-attitude-intention-behaviour relationship for predicting user intention adopt a new system. We choose to use the TAM (Technology Acceptance Model) because it is a widely used model and it has been validated in many contexts. It identifies two main constructs that fit our work well: perceived usefulness and perceived ease of use, while we add a new third construct, perceived Trust. Perceived usefulness (PU) measures "the degree to which a person believes that using a particular system would enhance his or her job performance," while perceived ease of use (PEoU) as measures "the degree to which a person believes that using a particular system would be free of effort" [9]. We describe Perceived Trust in detail below. The main advantage of TAM is that it helps to understand the users' motivation towards using information system and emerging technologies [13]

In this paper, we aim to understand the factors that motivate the adoption of m-commerce in Saudi Arabia from both a provider and customer perspective. Our focus on the case of 
Saudi Arabia is due to the current evidence that shows that "ecommerce is growing in slow adoption pattern" [14]. We propose a novel $\mathrm{m}$-commerce adoption model that extends TAM to suit the case of Saudi Arabia by defining a new construct, Perceived Trust (PT), that, besides PU and PEoU, serve the basis for attitudes towards adopting m-commerce. The model also defines a set of factors that form the independent variables that influence the constructs of PU, PEoU, and PT. The paper also outlines the methodology that is to be followed in order to evaluate the proposed model.

The remainder of this paper is organised as follows. The next section analyses related research work. Section III presents and details the research model adopted in this paper. Section IV outlines the methodology to be followed in our future work to evaluate the proposed model and concludes the paper.

\section{RELATED WORK}

In alignment with the scope of this paper, this section discusses works that addressed the potential for adopting mcommerce in Saudi Arabia. For this purpose, a number of studies have been identified including [15, 16, 17, 18, 19, 20]. For example, Makki and Chang [16] studied the potential influence of mobile applications usage on e-commerce in Saudi Arabia. Alkhunaizan and Love [17] conducted a study to examine the adoption factors. They focused on Perceived Ease of Use, Perceived Usefulness, Trust, Perceived financial cost, and Individual differences. AlSuwaidan and Mirza [20] studied the Saudi customer preferences behind the interface of the m-commerce mobile application. The study identified basic elements that the user interface should provide in order to encourage Saudi customers to adopt m-commerce. These elements include the ability to save payment information, viewing product images, and browsing ability, among others. Alfahl et al. [15] conducts an exploratory qualitative study which identified factors affecting the adoption of $\mathrm{m}$-commerce in Saudi banks.

These works provide valuable insights on the tendency to accept m-commerce in Saudi Arabia. Their findings confirm the potential of success due to the observed tendency of Saudi customers to use mobile applications and electronic commerce in general. However, these works suffer from two main limitations. First, they lack the investigation of the effect of independent variables that affect intermediate variables and consequently the ultimate objective of adopting m-commerce. For example, PEoU is an intermediate variable that can be affected by a set of dependent variables, including knowledge and culture. The effect of those dependent variables need to be considered to evaluate the effect of PEoU. Second, they focus on one party of the m-commerce actors, the customers, or a specific type of business (e.g. banks [18]). Other actors including business firms and governmental influence should also be of interest due to their effects on the adoption of mcommerce. In this paper, we outline a research model that addresses these limitations.

\section{The M-COMmerce ACCEPTANCE Framework}

This section presents and describes the research model that extends TAM for the case of m-commerce of Saudi Arabia, because the current evidence for effective adoption of ecommerce technologies in general is lacking [14]. The model defines factors (many unique to Saudi Arabia such as culture, social influence and government regulations) that influence the adoption of m-commerce in Saudi Arabia. These factors represent the independent variables of the proposed adoption model. For each factor, a hypothesis is proposed to specify the expected relation to the dependent variable, i.e. 'intention to adopt m-commerce in Saudi Arabia'. Figure 1 summarises the model illustrating its different layers and the factors that are detailed in the following subsections. The figure shows that the dependent variable to evaluate is the 'intention to adopt $\mathrm{m}$ commerce in Saudi Arabia'. This variable represents the goal of the research. This variable is determined by the intermediate variables, which represent the basic constructs of the research model. The basic constructs are in turn influenced by the set of adoption factors that represent the independent variables of the model.

\section{A. Basic Constructs (Intermediate variables)}

The basic constructs are factors that influence the behaviour of users with respect to their attitude to adopt a new technology. Three constructs are of interest in this model, namely the Perceived Ease of Use (PEoU), the Perceived Usefulness (PU), and the Perceived Trust (PT), which determine how helpful, convenient, and trusted is the m-commerce technology to use.

1) Perceived Ease of Use: Perceived Ease of Use (PEoU) is defined as "the degree to which a person believes that using a particular system would be free of effort" [9]. Many attributes can contribute to the PEoU in ICT in general and in $\mathrm{m}$-commerce in particulate such as Ease of understanding the system, Ease of finding information, and Ease of performing the required operations (e.g. placing orders, making payments, advertising goods/services etc.) [21]. The easier the user can understand how functionalities provided by the m-commerce system and find any information relevant to those functionalities, including products and services specifications and help and support, the more the user is willing to accept and adopt the system. This hypothesis has been proven in several studies in ICT $[22,23,24]$. Therefore, based on the above, hypothesis (H1) is defined as:

H1: If the Perceived Ease of Use of m-commerce technology is increased then this will lead to an increase in citizens intention to adopt m-commerce because citizens will have a better understanding of m-commerce.

2) Perceived Usefulness (PU): Perceived usefulness is defined as "the degree to which a person believes that use of the system will enhance his or her performance" [25]. This factor is a main construct in the basic TAM model and its extensions. It has been adopted and tested in many ICT studies $[26,27,28]$. It has been found that the extent to which the user finds the system useful plays a significant role in the continuation intention of using that system [29]. The widely 


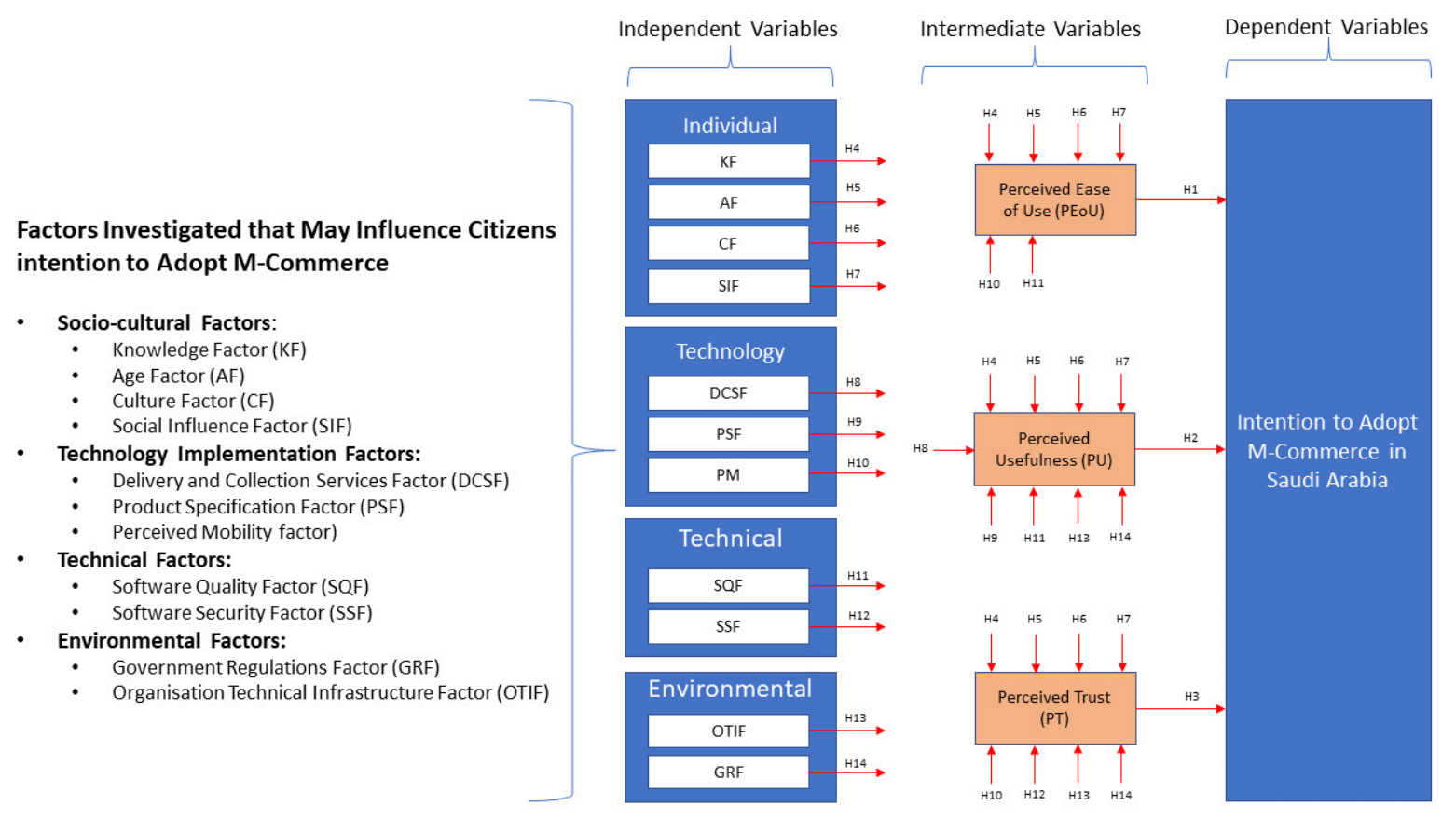

Fig. 1. The m-commerce Acceptance Framework

observed outcome is that PU positively influence the intention of adopting the ICT system. Therefore, based on the above, hypothesis (H2) is defined as:

H2: If the Perceived Usefulness of m-commerce technology is increased then this will lead to an increase in citizens intention to adopt m-commerce because citizens will better realise the advantage of $m$-commerce.

3) Perceived Trust (PT): One characteristic of mcommerce, and e-commerce in general, is that users will trade goods and services without physical interaction. This includes performing online payments through the electronic medium. Although users use this electronic medium to access internet, purchasing and paying over it is a different issue. It requires users' beliefs about the safety of this medium [30]. Consequently, users' trust of m-commerce is a key factor that influences the adoption of this technology. In the literature, there is no consensus on the definition of PT. Some definitions include Mcknight and Chervany's attempt which defined trust as "the extent to which one believes that the new technology usage will be reliable and credible" [31]. Another definition is "the extent to which an individual believes that using mcommerce is secure and has no privacy threats" [32]. These definitions imply that users' acceptance of m-commerce is not only related to PU and PEoU as a mobile technology, but also related to the customer belief that $\mathrm{m}$-commerce providers are safe to deal with is more important. Therefore, based on the above, hypothesis (H3) is placed.

H3: If we increase the Perceived Trust of m-commerce technology then this will lead to an increase in citizens intention to adopt m-commerce because citizens will have reduced uncertainty and fear of using $m$-commerce.

\section{B. Adoption factors (Independent variables)}

This paper studies the influence of factors on the adoption of m-commence. The conducted research will evaluate this influence on the intermediate variables of the model, which leads to understand the influence on the dependent variable 'intention to adopt m-commerce' in Saudi Arabia. The studied factors are categorised into Socio-cultural factors, Technology implementation factors, Technical factors, and Environmental factors and are described in the following.

1) Socio-cultural factors: Socio-cultural factors relate to residents who are potentially willing to use the new system or who are the target of innovators. Residents can be in different usage of the m-commerce system. Residents can be consumers, traders, innovation staff, and innovation managers, among others.

(a) Knowledge. The knowledge an individual possesses about new technologies in general affect their choice of using those technologies. Furthermore, the level of knowledge a firm's staff have affect the firm's ability to adopt $\mathrm{m}$-commerce. Therefore, the knowledge factor can be viewed from multiple dimensions, including, IT skills, education, and awareness.

- IT skills. The lack of IT skills present in various stakeholders can be a main barrier to adopting m-commerce [33]. Consumers who do not have appropriate knowledge of using mobile applications will prefer in-store shopping to buying goods over using m-commerce applications. Similarly, traders will avoid taking a risk of selling their 
goods through a mobile application if they do not have enough knowledge of how mobile applications work in an e-commerce solution. In addition, less experienced mcommerce innovation teams (developers and managers) may produce low-quality systems that may influence users to abandon m-commerce. We argue that improving the IT skills of various m-commerce stakeholders motivates them to accept and adopt m-commerce. This can be achieved through training stakeholders through seminars, workshops, and guidance in order to eliminate hesitation and increase confidence of adopting m-commerce [34].

- Education. Both the level and type of education may affect the intention to accept new technologies. Stakeholders who possess knowledge about e-commerce in general tend to accept a new m-commerce technology in Saudi Arabia. Similar attitudes could be expected from stakeholders who are knowledgeable of similar IT systems such as online banking or digital health systems as they are aware of the benefits of such systems.

- Technology awareness. Managers of SMEs in Saudi Arabia are expected to play a pivotal role in promoting mcommerce in the country. Therefore, the more the managers are aware of the advancement of m-commerce and similar technologies worldwide, the more they are eager to motivate the development of m-commerce applications for the Saudi market [35]. Furthermore, awareness of the availability of m-commerce, its functionalities and advantages is a pre-requisite step towards acceptance of it and the intention to use it. Awareness of m-commerce can be defined as the extent to which managers (or generally stakeholders) are aware of m-commerce technology and its advantages and potential. On the contrary, the lack of awareness of the technology will limit its adoption. This is evidenced by relevant research investigating the acceptance of m-banking in Saudi Arabia [36]. Their results revealed that the limited awareness of m-banking among Saudi residents resulted in limited acceptance and use of this service. Therefore, in order to positively influence the intention to use the m-commerce technology SME managers need to promote their awareness of the technology and the users' awareness of the significance of that technology.

Based on the above, hypothesis $\mathrm{H} 4$ is defined as:

H4: If citizens with higher levels of IT skills, education, and technology awareness report increased PEoU, PT and $\boldsymbol{P U}$ then this will lead to an increase in citizens intention to adopt m-commerce because they are more likely to be more accustomed to IT technologies in general.

(b) Age. The acceptance of a new technology may be strongly influenced by the age of the user. Studies revealed significant influence of age in many cases $[37,38]$. Results of some studies revealed negative attitude towards the new technology from consumers in older age brackets, whereas in others age had less significance [39]. Age is thought to have a significant influence on accepting m-commerce in Saudi Arabia as a developing country. Therefore, hypothesis H5 is defined as:

H5: If younger citizens report higher levels of PEoU, $\boldsymbol{P T}$ and $\boldsymbol{P U}$ then this will lead to an increase in citizens intention to adopt m-commerce because younger citizens better realise the advantage of $m$-commerce.

(c) Culture. The culture of any society develops over long periods of time and continually evolves. According to the Cultural Dimensions Theory [40], culture consists several dimensions including Individualism, Collectivism, Power, Masculinity and Femininity, among others. Such evolution and diversity made culture a complex term to define. However, it can be defined as "the values, beliefs, norms and behavioural patterns of a group of people in a society for national culture, staff of an organization for organizational culture, specific professions for professional" [41].

Culture has been considered as a moderator of technology acceptance in many studies from different perspectives $[42,43,44]$. The national level perspective has been widely adopted where the impacts of national values on technology acceptance were examined [45, 46]. Positive and negative correlation between national cultural values and technology acceptance were reported. For instance, Maitland and Bauer [45] found that that technology and acceptance are positively correlated with the impacts of national culture value. On the contrary, some studies revealed that national cultural values fail to anticipate the intention of users to accept the technology as the similarity of cultural values among all users cannot be guaranteed [46]. The above discussion makes the cultural factors at both national level and individual level interesting moderators to test.

The research model presented in this paper considers Image as a cultural factor. Image refers to the extent to which an individual considers that using new technologies promote their social status and appearance among their peers in the society [47]. This factor was considered in many studies $[48,49,50]$. It has been believed that the tendency towards using new technologies such as egovernment, may indicate a higher level of civilisation and modernisation an individual has. Similar context applies to e- and m-commerce where consumers in Saudi Arabia may find it prestigious that they carry out their purchase using their mobile phone. The influence of the Image factor can be more obvious with trading companies that can show off that they adopt m-commerce technologies and can deliver their product to their consumers doorsteps with few phone screen touches. Based on the above, hypothesis H6 is placed.

H6: If citizens, who engage with m-commerce technology so as to increase their social image among their peers, report higher levels of $\boldsymbol{P E o U}, \boldsymbol{P T}$ and $\boldsymbol{P U}$ then this will lead to an increase in citizens intention to adopt $\boldsymbol{m}$ commerce because they will be keen to promote their social image. 
(d) Social influence. Social influence refers to the extent to which external social factors impact individual behaviours [51]. People may become involved in various types of behaviour when they are influenced by other individual or group of people [10]. Social influence can be viewed as a result of the interaction between where people sense and realise what is accepted by society. Consequently, the behaviour of a certain group of people may influence others behavioural intention towards the acceptance of new technology. For this reason, Social influence has been widely considered as a main moderator of user behavioural intentions in many studies e.g. $[10,52]$. It is also one of essential constructs of the Unified Theory of Acceptance and Use of Technology Model (UTAUT). According to [53], five categories of a new technology adopters are defined, namely, innovators, early adopters, early majority, late majority, and laggards. Social influence can significantly affect each of the three latter categories, which obviously form the majority of the technology adopters. That also may explain the wide adoption of this factor in many innovative technologies including e-commerce [54], e- and m-government [55], fitness applications [56] among others. Based on the above, hypothesis $\mathrm{H} 7$ is formulated as:

H7: If citizens, influenced by other individual's or groups' behaviour towards m-commerce technology, report higher levels of PEoU, PT and PU then this will lead to an increase in citizens intention to adopt m-commerce because they will be keen to conform to other individual and group behaviour.

2) Technology implementation factors: Technology Implementation factors refer to a set of processes that are essential to realise the m-commerce technology. Each of them matches and replaces a process that exists in traditional commerce.

(a) Delivery and collection services. When an SME business produces a physical product that to be used by their consumers, at least one of two services are essential for the success of that SME, the delivery service or the clickand-collect service. The delivery service refers to the process of transporting purchased goods to an address specified by the consumer. The click-and-collect service refers to the process of delivering the purchased goods to a destination specified by the seller (sometimes the consumer selects from a set of destinations specified by the seller) along with the process of handing the goods over to the consumer from that destination. Any lack of provisioning for both services means that the mcommerce operation cannot be realised and, effectively, turns the system into an advertising system. In addition, the quality of these services influences the intention to accept m-commerce by the consumers. The more accurate and reliable the service, the more convincing and encouraging the m-commerce to accept [57] Based on the above, hypothesis $\mathrm{H} 8$ is formulated as:

H8: If citizens, who experience highly reliable delivery and/or click-and-collect services, report higher levels of $\boldsymbol{P U}$ then this will lead to an increase in citizens intention to adopt m-commerce because they will observe the usefulness of m-commerce.

(b) Product specification Product specification is information displayed to the consumer of the m-commerce system (or e-commerce in general) in order to describe the product features, properties, and recommend operating conditions. The accuracy of the specification is important for the customer satisfaction and the seller reputation. Meeting the customer expectations will encourage the customer to re-buy the product or reusing the service of the seller in addition to recommending it to other users. On the other hand, failing to achieve customer satisfaction will have the opposite effect. Repeatedly failing to meet customer satisfaction may discourage the customer usage of the m-commerce system at all. Therefore, although to maintain high accuracy of product specification is challenging for the sellers, they are still required to do so in order to make their m-commerce system a success [58]. Based on the above, hypothesis H9 is formulated. H9: If citizens, who observe m-commerce products, technology and services perform as expected, report higher levels of $\boldsymbol{P U}$ then this will lead to an increase in citizens intention to adopt m-commerce because they will observe the usefulness of m-commerce.

(c) Perceived mobility. Perceived mobility refers to the ability users have to access services and information any time while they move [59]. Thanks to the advancement of wireless technology that enabled efficient mobile computing. Benefiting from this technology, m-commence provides a credible extension to e-commerce. Users are no longer restricted to use static computing devices, such as desktop machines, to purchase goods, conduct sales, and access services as mobility allows them to access these functionalities while they move. This allows pervasive e-commerce and provides potential for wider use of technology. Subsequently, perceived mobility has been considered as a crucial factor that motivates users to adopt $\mathrm{m}$-technologies, including m-government [22], m-learning [60], and m-banking [59].

Mobile payment (m-payment) is another aspect of perceived mobility. It is a service that refers to the process of making payments using mobile devices [61]. Practically, one can argue that m-commerce can be realised without m-payment service, e.g. by on-delivery or on- collect payments. However, such service will limit the advantages of m-commerce and its usefulness. Consequently, the acceptance to use this service by the consumers is essential for wide adoption of $\mathrm{m}$-commerce technology. $\mathrm{Wu}$ et al. [62] conducted a study to understand the determinants of consumer acceptance of m-payment. Their findings reveal that risk and ease of use are main factors that encourage consumers to use this service. Risk refers to the expected loss associated to making a payment using the m-payment system. As the m-payment can be part of 
the $\mathrm{m}$-commerce systems, the associated risk is therefore a factor that affects the adoption of m-commerce. Based on the above view, hypothesis $\mathrm{H} 10$ is formulated.

H10: If citizens, who are able to access m-commerce services from their mobile devices regardless of their location, report increased PEoU and PT then this will lead to an increase in citizens intention to adopt m-commerce because they will observe the ease of usefulness and better trust m-commerce.

\section{3) Technical factors:}

(a) Software quality. This factor refers to a set of features and properties that software meets in order to satisfy the user requirements. The standard ISO 9126 [63] defines a set of attributes of software quality that concern users and developers. The development of m-commerce software system needs to take into software quality attributes in order to satisfy the users interacting with the system through their mobile devices. The user perception of the system quality may affect the whether he/she will proceed a commercial transaction and consequently may affect the intention to use m-commerce [64]. This study focuses on the following aspects of software quality:

- Presentation. The m-commerce software provides an environment where users utilise technology features. Presentation should take the characteristics of mobile devices into consideration. Such characteristics include limited computational and memory resources, small screen size, limited energy, and cost of data transfer. Presentation on mobile devices highly depends on text and a few number of colours and avoidance of images especially high resolution ones. The presentation should avoid too many colours as that negatively affects readability. Furthermore, as users' mobile devices are heterogeneous (i.e. different in features and capabilities) the m-commerce software may be customised according to the devices capabilities to improve readability and appearance. In short, userfriendly presentation may affect the perceived ease of use of the m-commerce system and consequently may affect the intention to use this technology.

- Reliability. Software reliability refers to the probability that m-commerce software will not exhibit failures for a certain period. This is a critical factor for the success of any system when software is a critical part of it. Software the produces errors, performs slowly, has unresponsive services, or contains broken links is unreliable. Previous studies show a strong correlation between reliability and This may affect the PEoU and PU.

- Navigation. The navigability of a software system refers to the existence of components that eases access to the information and functionalities of the system. These components include navigation bars, site maps and quick links. Each of these components should places in a proper place on the user interface; preferably following the W3C Mobile Web Best Practices 1.0 [65]. For example, the navigation bar should be position at the top of the in- terfacing page, the main contents appear on the page avoiding any extra scrolling, and any secondary element may be positioned at the bottom. The navigation factor is an important attribute of software quality and mainly affects the PEoU [64]. Based on the above discussion, hypothesis $\mathrm{H} 11$ is formulated.

H11: If citizens, who observe the quality of software based mobile products, report increased PEoU and PU then this will lead to an increase in citizens intention to adopt $\mathbf{m}$ commerce because they will observe the ease of use and usefulness of m-commerce.

(b) Software Security. It might be obvious that Software Security affects users' attitudes to adopting m-commerce. A security threat to the system may cause denial of service, disclosure of data, financial losses, and personal abuse, among others [66, 67]. All these threats negatively affect the user intention to adopt m-commerce. Therefore, $\mathrm{m}$ commerce software must implement security protection techniques including authorisation, authentication, data cryptography, and transactions encryption, among others in order to secure the system and reassure the user to adopt it a [68] . Based on that, hypothesis H12 is placed. H12: If citizens, who observe that m-commerce products and services are highly secure login and data protection, report increased $\boldsymbol{P T}$ then this will lead to an increase in citizens intention to adopt m-commerce because they will understand that their data will be less likely to be at risk.

4) Environmental factors.: The environment in which an mcommerce firm operates and the internal environment of that firm play an important role in the adoption of m-commerce. Therefore, we consider two environmental factors that relate to the state of the firm intending to adopt $\mathrm{m}$-commerce and the government role to support this new technology [15].

(a) Technology Infrastructure. Technology infrastructure is a requirement that firms need to carefully consider when they intend to adopt m-commerce. This involves communication, hardware, inter-organisation network, and staff IT expertise. Wireless networks technology is the key enables of m-commerce. Network coverage and bandwidth are the main features that determine the reliability, speed, and convenience of the communication over the wireless network. Limited network coverage and low bandwidth are indeed barriers to communications and affect comfort with using the m-commerce system. Therefore, firms need to study the national wireless infrastructure in Saudi Arabia and ensure that it is adequate to satisfy their business needs and their customers convenience. In addition, the firms may need to develop mobile application for their m-commerce. This requires hardware resources to build a data centre that hosts the application back-ends and maintains the system data. All the above requires staff expertise to study, build, an maintain the mcommerce system. Based on the above, hypothesis H13 is formulated. 
H13: If citizens, who observe that m-commerce products and services implementing secure suitable technological Infrastructure, report increased $\boldsymbol{P T}$ and $\boldsymbol{P U}$ then this will lead to an increase in citizens intention to adopt $m$ commerce because they will be more able to trust and use the m-commerce system.

(b) Governmental regulations. As discussed above, mcommerce brings many advantages to the consumers. These include comfortable and mobile shopping, search for products, and quick comparison of prices. However, trusting the m-commerce system is a crucial factor for adopting m-commerce. Consumer will purchase items from seller whom the consumers will not physically meet and will purchase items which they do not physically view. Consumers will pay for those items with doubt about the transactions' security. These issues and others necessitate the need for regulations that increase the trust of system. Therefore, a main factor to achieve this trust is to protect consumers through governmental legislation [69]. From a different perspective, producers need also governmental policies that protect their intellectual properties, trademarks, and domain names. They also need governmental polices for supporting technology implementation issues such as securing online payments, setting up exchange rates, and reducing taxes [67]. Based on that, hypothesis $\mathrm{H} 14$ is placed.

H14: If citizens, who observe that the Saudi government provides supportive and protective m-commerce technology infrastructure, report increased $\boldsymbol{P T}$ and $\boldsymbol{P U}$ then this will lead to an increase in citizens intention to adopt $\mathbf{m}$ commerce because they will feel they are less exposed to dishonest treatment and hence encourage their trust and use of m-commerce products and services.

\section{CONClusion And Future Research}

This paper has developed a new m-commerce acceptance framework for investigating the adoption of m-commerce in Saudi Arabia. The model takes into consideration both customer and businesses perspectives. It defines factors that affect the intention to use m-commerce technology. For the scope of this position paper, we have presented the model and discussed its dependent and independent factors. Our next work is to conduct a thorough study to collect data and analyse the model.

In more details, this position paper will be followed by a thorough study to analyse and evaluate the proposed model. The research methodology is two-fold: quantitative survey, and qualitative interview. The goal of the quantitative analysis is to investigate the customers' perspectives towards adopting m-commerce. This will be undertaken by a survey questionnaire which will be randomly distributed among potential mcommerce users in Saudi Arabia. The survey will be distributed electronically ${ }^{1}$ and we aim at a sample size of at least

\footnotetext{
${ }^{1}$ In the light of pandemic of Covid'19, only electronic means will be used to distribute the survey in order to comply with the safety and health advises.
}

500 participants. The questions of the survey will look at the extent to which each of the research model factors affects the decision of adopting m-commerce and the extent to which customers find m-commerce easy, useful, and trusted. All of the survey items will be measured using a five-point Likerttype scale with responses from "strongly disagree" to "strongly agree". The reliability of the research instrument will be examined using Cronbach's $\alpha$, which measures the extent to which a set of items measures a single factor. Resulting quantitative data will be analysed following a statistical method with target significance level of 0.05 . On the other hand, the goal of the qualitative analysis is to investigate the businesses perspectives towards adopting m-commerce. This will be undertaken by semi-structured interviews with marketing managers of private companies in Saudi Arabia. We aim at interviewing four to ten company managers. The interview will look at the advantages that m-commerce brings to the company in case the company utilises a m-commerce technology. Otherwise, the interview will investigate the reasons behind abandoning $\mathrm{m}$-commerce and if there are future plans to adopt $\mathrm{m}$-commerce.

\section{REFERENCES}

[1] T.-P. Liang and C.-P. Wei, "Introduction to the special issue: Mobile commerce applications," International journal of electronic commerce, vol. 8, no. 3, pp. 7-17, 2004.

[2] T. Natarajan, S. A. Balasubramanian, and D. L. Kasilingam, "Understanding the intention to use mobile shopping applications and its influence on price sensitivity," Journal of Retailing and Consumer Services, vol. 37, pp. 8-22, 2017.

[3] A. Y.-L. Chong, F. T. Chan, and K.-B. Ooi, "Predicting consumer decisions to adopt mobile commerce: Cross country empirical examination between china and malaysia," Decision Support Systems, vol. 53, no. 1, pp. 34 - 43, 2012. [Online]. Available: https://doi.org/10.1016/j.dss.2011.12.001

[4] L. Puspitasari and K. Ishii, "Digital divides and mobile internet in indonesia: Impact of smartphones," Telematics and Informatics, vol. 33, no. 2, pp. 472-483, 2016. [Online]. Available: https://doi.org/10.1016/j.tele.2015.11.001

[5] A. A. Alalwan, A. M. Baabdullah, N. P. Rana, K. Tamilmani, and Y. K. Dwivedi, "Examining adoption of mobile internet in saudi arabia: Extending tam with perceived enjoyment, innovativeness and trust," Technology in Society, vol. 55, pp. $100-110,2018$. [Online]. Available: https://doi.org/10.1016/j.techsoc.2018.06.007

[6] A. Puri-Mirza, "Smartphone penetration rate as share of the population in saudi arabia from 2017 to 2025," https://www.statista.com/statistics/625436/smartphoneuser-penetration-in-saudi-arabia/, publisher=Statista, note=Accessed: 05-08-2020, 2020.

[7] M. Alonazi, N. Beloff, and M. White, "Perceptions towards the adoption and utilization of m-government 
services: A study from the citizens' perspective in saudi arabia," in Information Technology for Management: Current Research and Future Directions. Springer, 2019, pp. 3-26.

[8] M. Nurunnabi, "Transformation from an oil-based economy to a knowledge-based economy in saudi arabia: the direction of saudi vision 2030," Journal of the Knowledge Economy, vol. 8, no. 2, pp. 536-564, 2017. [Online]. Available: https://doi.org/10.1007/s13132-0170479-8

[9] F. D. Davis, "A technology acceptance model for empirically testing new end-user information systems: Theory and results," Ph.D. dissertation, Massachusetts Institute of Technology, 1985.

[10] V. Venkatesh, M. G. Morris, G. B. Davis, and F. D. Davis, "User acceptance of information technology: Toward a unified view," MIS quarterly, pp. 425-478, 2003. [Online]. Available: https://doi.org/10.2307/30036540

[11] M. Fishbein and I. Ajzen, Belief, attitude, intention, and behavior: An introduction to theory and research. Reading, Mass.; London: Addison-Wesley, 1975.

[12] F. J. Rondan-Cataluña, J. Arenas-Gaitán, and P. E. Ramírez-Correa, "A comparison of the different versions of popular technology acceptance models," Kybernetes, 2015.

[13] G. Lala et al., "The emergence and development of the technology acceptance model (tam)," Marketing from Information to Decision, no. 7, pp. 149-160, 2014.

[14] M. AlQulaity and W. Bajaber, The Growth of ECommerce in Saudi Arabia and Its Influence on Saudi Women. GRIN Verlag, 2015.

[15] H. Alfahl, L. Houghton, and L. Sanzogni, "Mobile commerce adoption in saudi organizations: A qualitative study," Int. J. Enterp. Inf. Syst., vol. 13, no. 4, p. 31-57, Oct. 2017. [Online]. Available: https://doi.org/10.4018/IJEIS.2017100103

[16] E. Makki and L.-C. Chang, "Understanding the effects of social media and mobile usage on e-commerce: an exploratory study in saudi arabia," International management review, vol. 11, no. 2, p. 98, 2015.

[17] A. Alkhunaizan and S. Love, "Predicting consumer decisions to adopt mobile commerce in saudi arabia." in Proceedings of the Nineteenth Americas Conference on Information Systems, , August 2013, pp. 1-9.

[18] W. AlBalawi, I. Hidayat-ur Rehman et al., "The impacts of m-commerce on saudi banks," Journal of Management and Strategy, vol. 7, no. 2, p. 1, 2016.

[19] L. Rajabion, "Critical factors for adoption of mobile commerce services," International Journal of Business and Social Science, vol. 6, no. 12, pp. 26-35, 2015.

[20] L. AlSuwaidan and A. A. Mirza, "An investigation on user preferences of mobile commerce interface design in saudi arabia," in Mobile Web Information Systems, I. Awan, M. Younas, X. Franch, and C. Quer, Eds. Cham: Springer International Publishing, 2014, pp. 275 285 .
[21] M. R. Abbasi, M. A. Sarlak, A. Ghorbani, and H. A. Esfanjani, "Csfs of e-commerce admission in small and medium size enterprises (smes)," African Journal of Business Management, vol. 4, no. 16, p. 3480, 2010.

[22] E. Abu-Shanab and S. Haider, "Major factors influencing the adoption of m-government in jordan," Electronic Government, an International Journal, vol. 11, no. 4, pp. 223-240, 2015.

[23] T. Ramayah and J. Ignatius, "Impact of perceived usefulness, perceived ease of use and perceived enjoyment on intention to shop online," ICFAI Journal of Systems Management (IJSM), vol. 3, no. 3, pp. 36-51, 2005.

[24] A. B. Ozturk, A. Bilgihan, K. Nusair, and F. Okumus, "What keeps the mobile hotel booking users loyal? investigating the roles of self-efficacy, compatibility, perceived ease of use, and perceived convenience," International Journal of Information Management, vol. 36, no. 6, pp. 1350-1359, 2016.

[25] F. D. Davis, R. P. Bagozzi, and P. R. Warshaw, "User acceptance of computer technology: a comparison of two theoretical models," Management science, vol. 35, no. 8, pp. 982-1003, 1989.

[26] M. Reid and Y. Levy, "Integrating trust and computer self-efficacy with tam: An empirical assessment of customers' acceptance of banking information systems (bis) in jamaica," The Journal of Internet Banking and Commerce, vol. 13, no. 3, pp. 1-18, 1970.

[27] A. Molla and P. S. Licker, "E-commerce systems success: An attempt to extend and respecify the delone and maclean model of is success." J. Electron. Commerce Res., vol. 2, no. 4, pp. 131-141, 2001.

[28] A. Sambhanthan and A. Good, "Critical success factors for positive user experience in hotel websites: Applying herzberg's two factor theory for user experience modeling," International Journal of E-Services and Mobile Applications (IJESMA), vol. 5, no. 1, pp. 1-25, 2013.

[29] I. Brown and R. Jayakody, "B2c e-commerce success: A test and validation of a revised conceptual model," The Electronic Journal Information Systems Evaluation, vol. 11, no. 3, pp. 167-184, 2008.

[30] D. Gefen, E. Karahanna, and D. W. Straub, "Trust and tam in online shopping: An integrated model," $M I S Q$., vol. 27, no. 1, p. 51-90, Mar. 2003.

[31] D. H. McKnight and N. L. Chervany, "What trust means in e-commerce customer relationships: An interdisciplinary conceptual typology," International journal of electronic commerce, vol. 6, no. 2, pp. 35-59, 2001.

[32] T. T. Wei, G. Marthandan, A. Y.-L. Chong, K.-B. Ooi, and S. Arumugam, "What drives malaysian m-commerce adoption? an empirical analysis," Industrial management \& data systems, 2009.

[33] A. N. H. Zaied, "Barriers to e-commerce adoption in egyptian smes," International Journal of Information Engineering and Electronic Business, vol. 4, no. 3, p. 9, 2012.

[34] R. A. Saif-Ur-Rehman, "A study of barriers to e- 
commerce adoption among smes in malaysia," University of Modern Sciences, vol. 1, no. 1, pp. 45-58, 2016.

[35] L. V. Huy and P. Filiatrault, "The adoption of ecommerce in smes in vietnam: a study of users and prospectors," PACIS 2006 Proceedings, p. 74, 2006.

[36] A. N. Alkhaldi, "Adoption of mobile banking in saudi arabia: An empirical evaluation study," International Journal of Managing Information Technology, vol. 8, no. 2, pp. 1-14, 2016.

[37] K. Dickersin, Y.-I. Min, and C. L. Meinert, "Factors influencing publication of research results: follow-up of applications submitted to two institutional review boards," Jama, vol. 267, no. 3, pp. 374-378, 1992.

[38] P. Brauner, J. van Heek, and M. Ziefle, "Age, gender, and technology attitude as factors for acceptance of smart interactive textiles in home environments," in Proceedings of the 3rd International Conference on Information and Communication Technologies for Ageing Well and e-Health, ICT4AgingWell, 2017.

[39] R. W. Berkowsky, J. Sharit, and S. J. Czaja, "Factors predicting decisions about technology adoption among older adults," Innovation in aging, vol. 1, no. 3, p. igy002, 2017.

[40] G. Hofstede, Culture's consequences: Comparing values, behaviors, institutions and organizations across nations. Sage publications, 2001.

[41] K. Leung, R. S. Bhagat, N. R. Buchan, M. Erez, and C. B. Gibson, "Culture and international business: Recent advances and their implications for future research," Journal of international business studies, vol. 36, no. 4, pp. 357-378, 2005.

[42] S. Sunny, L. Patrick, and L. Rob, "Impact of cultural values on technology acceptance and technology readiness," International Journal of Hospitality Management, vol. 77, pp. 89-96, 2019.

[43] M. Ali, V. Weerakkody, and R. El-Haddadeh, "The impact of national culture on e-government implementation: A comparison case study," 2009.

[44] M. Alonazi, "Mgaum: a new framework for the mobile government service adoption in saudi arabia," Ph.D. dissertation, University of Sussex, 2019.

[45] C. F. Maitland and J. M. Bauer, "National level culture and global diffusion: The case of the internet," Culture, technology, communication: Towards an intercultural global village, pp. 87-128, 2001.

[46] J. Meng, K. M. Elliott, and M. C. Hall, "Technology readiness index (tri): Assessing cross-cultural validity," Journal of International Consumer Marketing, vol. 22, no. 1, pp. 19-31, 2009.

[47] G. C. Moore and I. Benbasat, "Development of an instrument to measure the perceptions of adopting an information technology innovation," Information systems research, vol. 2, no. 3, pp. 192-222, 1991.

[48] D. Gilbert, P. Balestrini, and D. Littleboy, "Barriers and benefits in the adoption of e-government," International Journal of Public Sector Management, 2004.
[49] C. W. Phang, Y. Li, J. Sutanto, and A. Kankanhalli, "Senior citizens' adoption of e-government: In quest of the antecedents of perceived usefulness," in Proceedings of the 38th annual Hawaii international conference on system sciences. IEEE, 2005, pp. 130a-130a.

[50] L. L. Tung and O. Rieck, "Adoption of electronic government services among business organizations in singapore," The Journal of Strategic Information Systems, vol. 14, no. 4, pp. 417-440, 2005.

[51] J. Fang, Z. Zhao, C. Wen, and R. Wang, "Design and performance attributes driving mobile travel application engagement," International Journal of Information Management, vol. 37, no. 4, pp. 269 - 283, 2017. [Online]. Available: https://doi.org/10.1016/j.ijinfomgt.2017.03.003

[52] Y. Lu, T. Zhou, and B. Wang, "Exploring chinese users' acceptance of instant messaging using the theory of planned behavior, the technology acceptance model, and the flow theory," Computers in human behavior, vol. 25, no. 1, pp. 29-39, 2009.

[53] E. M. Rogers, Diffusion of Innovations: Modifications of a Model for Telecommunications. Berlin, Heidelberg: Springer Berlin Heidelberg, pp. 25-38. [Online]. Available: https://doi.org/10.1007/978-3-642-79868-9_2

[54] Y. A. Kim and J. Srivastava, "Impact of social influence in e-commerce decision making," in Proceedings of the ninth international conference on Electronic commerce, 2007, pp. 293-302.

[55] S. Z. Ahmad and K. Khalid, "The adoption of mgovernment services from the user's perspectives: Empirical evidence from the united arab emirates," International Journal of Information Management, vol. 37, no. 5, pp. 367-379, 2017.

[56] A. D. Beldad and S. M. Hegner, "Expanding the technology acceptance model with the inclusion of trust, social influence, and health valuation to determine the predictors of german users' willingness to continue using a fitness app: A structural equation modeling approach," International Journal of Human-Computer Interaction, vol. 34, no. 9, pp. 882-893, 2018.

[57] A. Azam, P. F. Qiang, and M. I. Abdullah, "Consumers' e-commerce acceptance model: Antecedents of trust and satisfaction constructs," in 2012 IEEE Business, Engineering \& Industrial Applications Colloquium (BEIAC). IEEE, 2012, pp. 371-376.

[58] P. V. Hande, D. Ghosh et al., "A comparative study on factors shaping buying behaviour on $b 2 b$ and $b 2 c$ e-commerce platforms in india," EXCEL International Journal of Multidisciplinary Management Studies, vol. 5, no. 3, pp. 1-10, 2015.

[59] Y.-S. Yen and F.-S. Wu, "Predicting the adoption of mobile financial services: The impacts of perceived mobility and personal habit," Computers in Human Behavior, vol. 65 , pp. 31-42, 2016.

[60] A. K. M. Almasri, "The influence on mobile learning based on technology acceptance model (tam), mobile 
readiness (mr) and perceived interaction (pi) for higher education students," International Journal of Technical Research and Applications, vol. 2, no. 1, pp. 05-11, 2014.

[61] L.-d. Chen, "A model of consumer acceptance of mobile payment," International Journal of Mobile Communications, vol. 6, no. 1, pp. 32-52, 2008.

[62] J. Wu, L. Liu, and L. Huang, "Consumer acceptance of mobile payment across time," Industrial Management \& Data Systems, 2017.

[63] ISO/IEC9126-1:2001, "Software engineering - product quality - part 1: Quality model," International Organization for Standardization, Geneva, CH, Standard, Jun. 2001.

[64] J. D. Garofalakis, A. Stefani, V. Stefanis, and M. N. Xenos, "Quality attributes of consumer-based mcommerce systems." in ICE-B, 2007, pp. 130-136.

[65] W. W. W. Consortium et al., "Mobile web best practices
1.0: Basic guidelines," 2008.

[66] S. Alabi, M. White, and N. Beloff, "Contactless palm vein authentication security technique for better adoption of e-commerce in developing countries," in Science and Information Conference. Springer, 2020, pp. 380-390.

[67] H. Zhang and S. C. Okoroafo, "An e-commerce key success factors framework for chinese sme exporters," International Journal of Economics and Finance, vol. 6, no. 1, pp. 129-137, 2014.

[68] E. P. Hansel and R. A. A. Vianna, "E-commerce based payment system with authentication of electronic invoices," May 19 2016, uS Patent App. 14/789,240.

[69] E. Makki and L.-C. Chang, "E-commerce acceptance and implementation in saudi arabia: previous, current and future factors," The International Journal of Management Research and Business Strategy, vol. 4, no. 3, pp. 29-44, 2015. 